\title{
Penanaman Mangrove Sebagai Upaya Pencegahan Abrasi di Desa Socah Kabupaten Bangkalan
}

\author{
Achmad Fachrudin Syah \\ Program Studi Ilmu Kelautan Fakultas Pertanian \\ Universitas Trunojoyo Madura \\ E-mail : fachrudin@trunojoyo.ac.id \\ DOI: https://doi.org/10.21107/pangabdhi.v6i1.6909 \\ Naskah diterima 2 Februari 2020, Revisi 30 Maret 2020, Terbit 19 April 2020
}

\begin{abstract}
Abstrak
Ekosistem hutan mangrove merupakan habitat penting bagi organisme kelautan dan sebagai penjaga pantai dari abrasi. Salah satu daerah yang mempunyai hutan mangrove dan cukup rentan dengan terjadinya abrasi adalah Desa Socah di Kabupaten Bangkalan. Kegiatan ini bertujuan untuk meningkatkan kesadaran masayarakat tentang pentingnya mangrove dalam mencegah terjadi abrasi, khusunya di Desa Socah. Kegiatan ini melibatkan pemuda karang ateruna dan warga Desa. Secara umum, kegiatan ini berjalan dengan lancar dan diikuti dengan antusias yang cukup tinggi oleh seluruh peserta. Diharapkan dengan adanya kegiatan ini, masyarakat Socah dapat memahami dan mengambil manfaat besar yang dimiliki oleh mangrove serta mencegah Desa Socah dari abrasi.
\end{abstract}

Kata Kunci : Socah, penanaman, mangrove, abrasi

\begin{abstract}
The mangrove forest ecosystem is an important habitat for marine organisms and as a lifeguard from abrasion. One area that has mangrove forests and is quite vulnerable to abrasion is the Socah Village in Bangkalan Regency. This activity aims to increase public awareness about the importance of mangroves in preventing abrasion, especially in Socah Village. This activity involved ateruna youth and village residents. In general, this activity ran smoothly and was followed with high enthusiasm by all participants. It is hoped that with this activity, the Socah community can understand and take advantage of the huge benefits of mangroves and prevent Socah Village from abrasion.
\end{abstract}

Key Words : Socah, plantation, mangrove, abration

\section{PENDAHULUAN}

Hutan mangrove adalah hutan yang terdapat di daerah pantai yang selalu atau secara teratur tergenang air laut dan terpengaruh oleh pasang surut air laut tetapi tidak terpengaruh oleh iklim. Hutan mangrove adalah sebutan umum yang digunakan untuk menggambarkan suatu varietas komunitas pantai tropik yang didominasi oleh beberapa spesies pohon tertentu atau semaksemak yang mempunyai kemampuan untuk tumbuh dalam perairan asin. Hutan mangrove dicirikan oleh tumbuhan dari 9 genus (Avicennia, Snaeda, Laguncularia, Lumnitzera, Conocarpus, Aegicera, Aegialitis, Rhizophora, Brugiera, Ceriops, Sonneratia), memiliki akar napas (pneumatofor), zonasi (Avicennia/Sonneratia, Rhizophora, Bruguiera, Ceriops, Nypa), tumbuh pada substrat tanah berlumpur/berpasir dan variasinya, salinitas bervariasi. Hutan mangrove adalah hutan yang tumbuh di wilayah pesisir yang selalu atau secara teratur tergenang air laut dan terpengaruh pasang surut laut tetapi tidak oleh iklim (Nybakken, 1982).

Hutan mangrove merupakan daerah marjinal, namun di dalamnya tersimpan potensi yang cukup besar. Hutan mangrove sebagai salah satu sumber daya di wilayah pesisir memiliki potensi yang dapat dimanfaatakan secara tidak langsung, maupun secara ekonomis (langsung). Manfaat yang dapat dirasakan langsung diantaranya berupa kayu pohon mangrove yang dapat digunakan sebagai bahan bangunan, kayu bakar, bahan untuk membuat arang, pulp, tunnin (zat penyamak), chipwood, dan sebagai obat tradisional. Di pandang dari segi ekologi (lingkungan) hutan mangrove merupakan tempat berlindung dan tempat mencari makan bagi kehidupan fauna (ikan, crustacea), serta 
pengeksport bahan organik yang berguna untuk menunjang kelestarian biota akuatik (Heald \& Odum, 1972; Macnae, 1974; Barnes, 1974). Lahan mangrove dalam kemampuannya berperan mendukung ekosistem lingkungan fisik dan lingkungan biota. Secara fisik mangrove juga berperan sebagai penahan ombak, penahan angin, pengendali angin, perangkap sedimen, dan penahan intrusi air asin, sedangkan perannya di lingkungan biota yaitu sebagai tempat persembunyian, tempat perkembangbiakan berbagai macam biota air (ikan, udang, moluska, reptilia, mamalia dan burung). Selain itu mangrove juga dianggap sebagai penyumbang zat hara yang berguna untuk kesuburan perairan di sekitarnya.

Desa Socah merupakan daerah pesisir yang cukup padat penduduknya dan dekat dengan Pelabuhan Tanjung Perak Surabaya dan Pelabuhan Kamal, yang masih memiliki hutan mangrove. Kondisi demikian akan mendorong Desa Socah untuk mengalami abrasi. Oleh karena itu penanaman mangrove di Desa Socah diharapkan dapat mengurangi dan mencegah terjadi abrasi yang mungkin terjadi. Aksi penanaman mangrove dilakukan dengan tujuan mewujudkan kepedulian masyarakat terhadap lingkungan dan pencegahan terjadinya abrasi.

\section{METODE}

Kegiatan pengabdian masyarakat ini dilakukan pada tanggal 31 Desember 2019 di Desa Socah, Kabupaten Bangkalan, Madura. Bahan yang digunakan dalam kegiatan ini adalah bibit mangrove (Rhizopora mucronata), tali rafia, dan ajir. Bibit mangrove diperoleh dari Pembibitan Mangrove Coastal and Marine Biodiversity Reserver (CMBR) Lembung Peseser, Sepulu - Bangkalan.

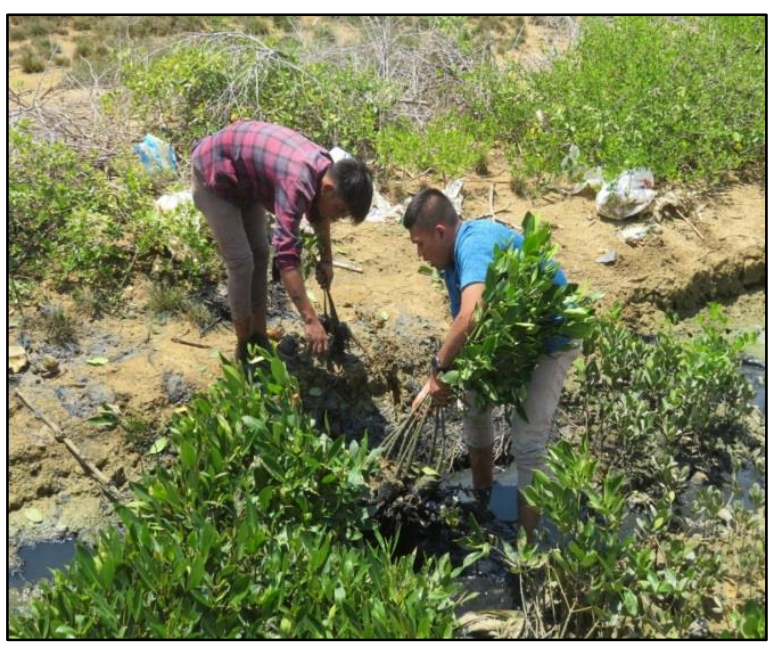

Gambar 1. Persiapan Bibit Mangrove

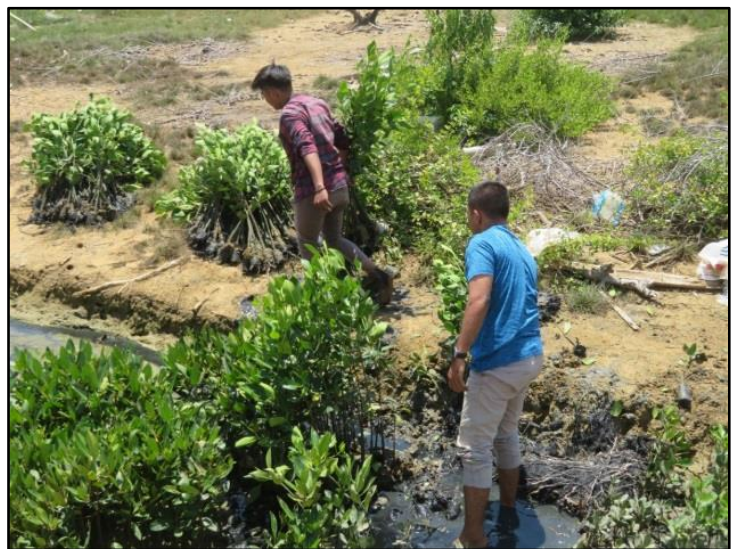

Gambar 2. Persiapan Penanaman Bibit Mangrove

\section{HASIL DAN PEMBAHASAN}

Mangrove dan Habitat Mangrove

Mangrove adalah tumbuhan yang mempunyai kemampuan adaptasi yang sedemikian rupa sehingga mampu hidup di lingkungan berkadar garam tinggi seperti lingkungan laut. Sedangkan hutan mangrove adalah komunitas vegetasi pantai tropis dan subtropis yang didominasi beberapa jenis pohon mangrove yang mampu tumbuh dan berkembang pada daerah pasang surut pantai berlumpur. Mangrove banyak dijumpai di pantai - pantai terlindung atau pantai yang datar serta di tempat pertemuan antara muara sungai dan air laut yang kemudian menjadi pelindung daratan dan gelombang laut yang besar. Mangrove tidak tumbuh dipantai yang terjal dan berombak besar dengan arus pasang surut yang kuat. Hal ini disebabkan karena ombak yang besar tidak memungkinkan terjadinya pengendapan lumpur dari pasir, sebagai substrat yang diperlukan untuk pertumbuhannya (Nontji, 1993).

\section{Faktor yang Mempengaruhi Eksistensi Mangrove}

Sebagai daerah peralihan antara laut dan daratan, hutan mangrove mempunyai gradien sifat lingkungan yang sangat ekstrim. Pasangsurut air laut menyebabkan terjadinya perubahan beberapa faktor lingkungan yang besar, terutama suhu dan salinitas. Oleh karena itu, hanya beberapa jenis tumbuhan yang memiliki daya toleransi yang tinggi terhadap lingkungan yang ekstrim tersebut saja yang mampu bertahan hidup dan berkembang di dalamnya. Kondisi yang terjadi tersebut juga menyebabkan rendahnya keanekaragaman jenis, namun di sisi lain kepadatan populasi masing - masing jenis umumnya tinggi. Walaupun habitat hutan mangrove bersifat khusus, namun masing - 
masing jenis tumbuhan memiliki kisaran ekologi tersendiri, sehingga kondisi ini menyebabkan terbentuknya berbagai macam komunitas dan bahkan permintakatan atau zonasi, sehingga kompetisi jenis berbeda dari satu tempat ke tempat lainnya. Munculnya fenomena permintakatan yang terjadi pada hutan mangrove tersebut sangat berkaitan erat dengan beberapa faktor, antara lain adalah tipe tanah, keterbukaan areal mangrove dari hempasan ombak, salinitas dan pengaruh pasang-surut (Soerianegara, 1971; Chapman, 1976; Kartawinata \& Waluyo, 1977).

Pengaruh tipe tanah atau substrat tersebut, sangat jelas terlihat pada jenis Rhizophora, misalnya pada tanah lumpur yang dalam dan lembek akan tumbuh dan didominasi oleh Rhizophora mucronata yang kadang-kadang tumbuh berdampingan dengan Avicennia marina, kemudian untuk Rhizophora stylosa lebih menyukai pada pantai yang memiliki tanah pasir atau pecahan terumbu karang, dan biasanya berasosiasi dengan jenis Sonnerafia alba. Sedangkan untuk jenis Rhizophora apiculata hidup pada daerah transisi. Selain tipe tanah, kondisi kadar garam atau salinitas pada substrat juga mempunyai pengaruh terhadap sebaran dan terjadinya permintakatan.

Berbagai macam jenis tumbuhan mangrove mampu bertahan hidup pada salinitas tinggi, namun jenis Avicennia merupakan jenis yang mampu hidup bertoleransi terhadap kisaran salinitas yang sangat besar. MacNae (1968) menyebutkan bahwa Avicennia marina mampu tumbuh pada salinitas sangat rendah sampai 90\%o, sedangkan Sonneratia sp. umumnya hidup pada salinitas yang tinggi, kecuali Sonnerafia casiolaris (sekitar 10\%). Jenis Bruguiera sp biasanya tumbuh pada salinitas maksimum sekitar 25\%o, sedangkan jenis Ceriops tagal, Rhizophora mucronata dan Rhizophora stylosa mampu hidup pada salinitas yang relatif tinggi. Disamping faktor-faktor tersebut di atas, pasangsurut air laut juga mempunyai pengaruh terhadap jenis tumbuhan mangrove yang tumbuh pada suatu daerah. Watson dalam Kartawinata et al., (1979) memberikan gambaran tentang korelasi antara tingginya genangan air pasang dan lama genangan, dengan jenis tumbuhan mangrove.

\section{Rhizopora mucronata}

Rhizopora mucronata merupakan salah satu jenis mangrove yang ada di Desa Socah. Manrove ini mempunyai nama daerah diantaranya bakau, bakau gundul, bakau genjah dan bangko. Spesies ini termasuk ke dalam family Rhizophoraceae dan banyak ditemukan pada daerah berpasir serta daerah pasang surut air laut. Tanaman bakau dapat tumbuh hingga ketinggian $35-40 \mathrm{~m}$. Tanaman bakau mempunyai kulit luar berwarna coklat keabuabuan sampai hitam, dengan bagian luar kulit terlihat retak-retak serta memiliki batang silindris. Akar tanaman ini menyerupai akar tunjang (akar tongkat). Akar tunjang digunakan sebagai alat pernafasan karena memiliki lentisel pada permukaannya.

Akar tanaman tersebut tumbuh menggantung dari batang atau cabang yang rendah dan dilapisi semacam sel lilin yang dapat dilewati oksigen tetapi tidak tembus air (Murdiyanto 2003). Tanaman bakau memiliki daun melonjong, berwarna hijau dan mengkilap dengan panjang tangkai 17-35 mm. Tanaman ini umumnya memiliki bunga berwarna kuning yang dikelilingi kelopak berwarna kuning-kecoklatan sampai kemerahan. Proses penyerbukan dibantu oleh serangga dan terjadi pada April sampai dengan Oktober. Penyerbukan menghasilkan buah berwarna hijau yang umumnya memiliki panjang $36-70 \mathrm{~cm}$ dan diameter $2 \mathrm{~cm}$.
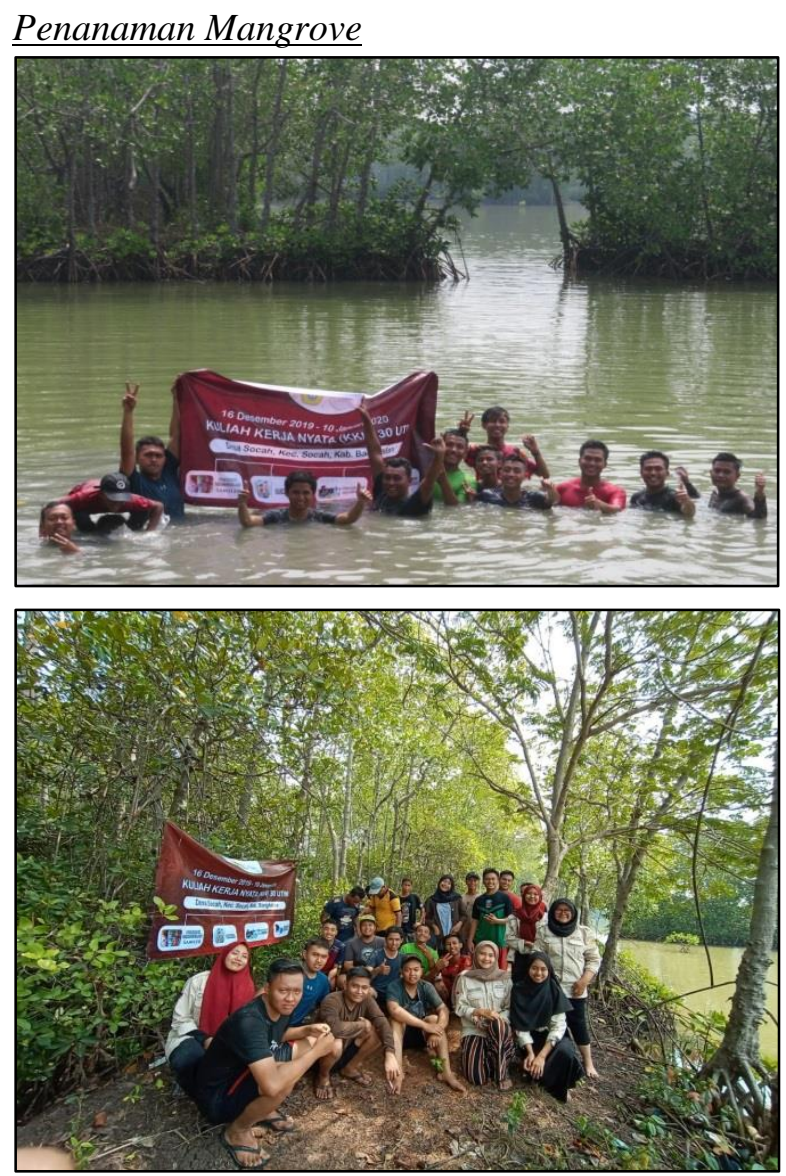

Gambar 2. Mahasiswa KKN di Lokasi Penanaman Mangrove 
Dalam rangka mensukseskan penanaman mangrove ini, beberapa hal telah dilakukan diantaranya melakukan sosialisasi program penanaman bibit mangrove kepada perangkat Desa, pemuda karang taruna dan seluruh warga Dusun Kejawan di Desa Socah. Survey lokasi juga dilakukan untuk menentukan daerah yang cocok untuk penanaman mangrove.
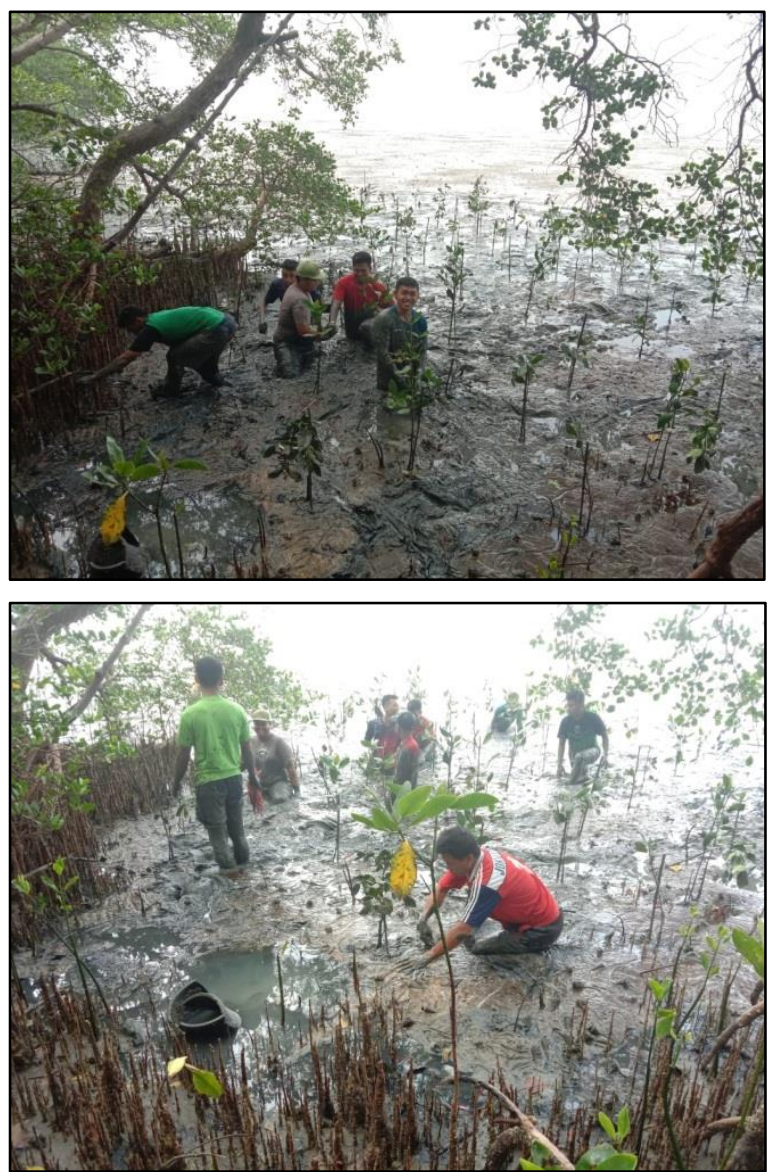

Gambar 3. Proses Penanaman Mangrove

\section{KESIMPULAN}

Kegiatan pengabdian penanaman mangrove di Desa Socah sangat penting dilakukan karena dapat meningkatkan pemahaman masyarakat akan pentingnya mangrove dan juga dapat mengurangi atau mencegah terjadinya abrasi pantai di Desa Socah.

\section{DAFTAR PUSTAKA}

Barnes, R.S.K. 1974. Estuarine Biology. In : Studies in Biology No. 49. Edward Arnold Ltd. (pbl) London, 76 pp.
Chapman, V.J. 1976. Mangrove Vegetation. J. Cramer, Inder A. R. Gantner Verlag Kommanditgesellschaft, FL-9490 VADUZ, p. 447.

Heald, E.J. and Odum, W.E. 1972. The Contribution of Mangrove Swamps to Florida Fisheries. Gulf and Carib. Fish Inst. Proc. nd 22 . Ann. Sess : 130 -135.

Kartawinata, K., Adisoemarto, S., Soemodihardjo, S. dan Tantra, I.G.M. (1979) Status Pengetahuan Hutan Bakau di Indonesia. Pros. Sem. Ekos. Hutan Mangrove: 21-39.

Kartawinata, K. and Waluyo, E. B. 1977. A Preliminary Study of The Mangrove Forest on Pulau Rambut, Jakarta Bay. Mar. Res. Indon. 18:119-129.

Kusmana,C., Wilarso, S., Hilwan, I., Pamoengkas, P., Wibowo, C., Tiryana, T., Triswanto, A., Yunasfi, \& Hamzah. 2003. Teknik Rehabilitasi Mangrove. Bogor: Fakultas Kehutanan IPB

MacNae, W. 1968. A General Account of The Fauna and Flora of Mangrove Swamps and Forests In The Indo-West Pacific Region. Adv. Mar. Biol. 6: 73-270.

Macnae, W.E. 1974. Mangrove Forest and Fisheries. FAO.IOFC/DEF/64 : 35 pp.

Nybakken, J. W. 1982. Marine Biology: An Ecological Approach. Harper \& Row, N.Y. $446 \mathrm{p}$.

Nontji A. 1993. Laut Nusantara. Jakarta: Djambatan.

Soerianegara, I. 1971. Characteristic of Mangrove Soil of Java. Rimba Indononesia 15:141-150. 
2 Jurnal Pangabdhi 